\title{
The Receptacle for all that is Monstrous and Vile: The Island Asylum in Scorsese's Shutter Island
}

\author{
Jessica Balanzategui \\ James Cook University
}

\begin{abstract}
In Shutter Island (Scorsese, 2010), the gothic mental asylum metonymises the symbolic powers of madness. The asylum's position on an isolated island encodes a dichotomy between nature and culture homologous to the film's depiction of madness and rationality, while marking the asylum as an uncanny domain subversive of the rational structures of mainland society.
\end{abstract}

$\mathrm{M}$ artin Scorsese's Shutter Island (2010) features a gothic mental asylum on a treacherous island, a setting that augments both the sense of inescapable confinement and the uncanny qualities of madness represented by the asylum. Shutter Island is a metonymic example of a subgenre of horror films which I call the "asylum horror film”, horror films which centralise monstrous asylums as a source of dread and fear. The asylums in these films, as in Shutter Island, often reflect the myths and symbolism surrounding madness deconstructed by Foucault in Madness and Civilisation. The figure of the asylum is central to Foucault's work, a fortress of confinement which he argues came to represent "the receptacle for all the most monstrous and vile things to be found in society" (192). Yet even so "the Horror that ... surrounded the fortresses of confinement also exercised an irresistible attraction" (197). Thus it is perhaps fitting that the asylum has become a central figure in the horror film, a genre built around the paradoxical forces of intense fear and irresistible attraction. In Shutter Island, as in many horror films which feature monstrous asylums or "madhouses", the gothic mental asylum metonymises the symbolic powers of madness. In this film, the asylum's position on an isolated island encodes a dichotomy between nature and culture homologous to the film's depiction of madness and rationality, while marking the asylum as an uncanny domain subversive of the rational structures of mainland society. Throughout the film, the battle to constrain the volatile powers of madness becomes psychotopographically mapped upon the whole island setting. Furthermore, the island underscores and intensifies the dichotomous relationship between the asylum's psychologists and the mad central character.

The island setting has become a relatively common trope in filmic and literary stories of confinement and horror. By definition, the island is isolated and segregated from the "normal society" of the mainland, rendering it a potent icon of inescapable confinement, often inhabited by a malevolent genius loci. These qualities are highlighted in H.G. Wells' The Island of Dr. Moreau (and two like-named film remakes, directed by Don Taylor (1977) and John Frankenheimer (1996)), in which a mad scientist creates a colony of part human, part animal creatures on an island; and in island prison films such as Papillon (Franklin Schaffner, 1973). More recently, the television series Lost (J.J. Abrams, 2004-2010) featured an uncanny, inescapable island as the central enigma. In Shutter Island, the gothic asylum shares and augments these features of the island of confinement, heralding an uncanny dimension subversive of normal society. The gothic architecture of the Shutter Island asylum - and 
other such gothic asylums in Asylum (Roy Baker, 1972) and Session 9 (Brad Anderson, 2001) - dramatises the clash between the irrational, abject world of madness and the often sinister psychological powers aimed at suppressing this madness. Thus the combination of the island of confinement and the gothic asylum building constructs a dimension of menace, mystery and the uncanny.

In Shutter Island, the world of madness and the world of truth and reason are cast as warring binary opposites - as head psychologist Dr. Cawley (Ben Kingsley) says to protagonist and madman Andrew (Leonardo Di Caprio) at one point in the film, "we're on the frontlines of a war, old boy". This "war" becomes mapped onto the island asylum setting through the battle between nature and culture ingrained upon the island; the imposing brick buildings and manicured, controlled structure of the asylum grounds and gardens is contrasted with (and sometimes invaded by) the wild and untamed nature of the island throughout the film. The ambience of war embedded upon the island is internalised by Andrew, expressed in his delusions and memories of Nazi death camps and paranoias about the psychologists' Nazilike experiments. The viewer shares in this warring dichotomy between madness and rationality by being welded to Andrew's delusional point of view, yet the audience is not made aware of the central character's madness until the end of the film. Andrew has created an intricate system of delusions which repress the memory that his wife drowned their three children, and that he then murdered her. In Andrew's delusional world he has recast himself as “Teddy Daniels”, a heroic United States Marshal who has come to Shutter Island to explore the disappearance of a patient, Rachel Solando.

The representation of delusion is entwined with the mechanics of detective narrative, as a film noir aesthetic permeates the film. This aesthetic is typical of Scorsese's oeuvre ${ }^{1}$, and unites the narrative of delusion and the site of the asylum with the ambience of film noir, invoking disorientation, alienation, paranoia and themes of fractured masculinity. The layering of horror and film noir in turn influences spectator participation and expectations, encouraging audiences to accept “Teddy's" hardboiled persona and to share in his paranoid perceptions. Thus in Shutter Island the spectator shares in the disorientating undermining of Andrew's identity, through the revelation that they have not been engaged in the anfractuous mechanics of detective narrative but in fact have been sharing in Andrew's delusion. The conflict between the detective narrative and the narrative of delusion further underscores the central thematic dichotomy between madness and rationality, which is realised in the visual construction of the asylum through the nature-culture opposition.

Ashecliffe Asylum is presented as an uncanny and dangerous alternative dimension, cordoned off from the world of the rational and the normal represented by the mainland. The film opens in a blinding, blurring fog, a fog which suggests that the viewer is emerging into an uncanny dimension, one segregated from any recognisable, conventional society. The fog also suggests an obscuring of reality, a condition central to the film's Surrealist rendering of madness. The rippling water and looming, ominous boat which gradually emerges from this fog evokes Foucault's discussion of the "Ship of Fools", a feature of European literature and society of the seventeenth century in which the mad were exiled from the community on large boats. Foucault asserts that this ship had a dual role: to separate the mad from the

\footnotetext{
${ }^{1}$ While Scorsese's filmography is extensive and varied, the majority of his films — and those that are most respected - can be considered neo-noir, with plots revolving around crime and gangsters. These include Mean Streets (1973), Taxi Driver (1976), Goodfellas (1990), Casino (1995) and The Departed (2006), which also starred Di Caprio.
} 
rational community on the mainland (a role also played by Shutter Island itself) and to put the madman on a symbolic search for his reason - a search which emerges as the central quest in Shutter Island.

Furthermore, Foucault asserts that "water and madness have long been linked in the dreams of European man" (9). Water remains a significant motif throughout the film, being a pivotal symbolic component of Andrew's madness and thus inherent to the narrative structure of the film. The ocean surrounds Shutter Island, serving as the central partition from the normality of the mainland. This wide, treacherous divide highlights the portrayal of Shutter Island as a mysterious alternative dimension contaminated by the uncanny discourse of madness. Throughout history water has frequently emerged as a symbolic purification agent in the "cleansing" of unreason and madness. This association can be seen in the Ship of Fools, as well as in the eighteenth and nineteenth century practice of submerging patients in water for long periods of time, which Foucault describes as a symbolic "christening” into the world of reason (164). However in a number of asylum horror films, such as Gothika (Mathieu Kassovitz, 2003) and Asylum (David Ellis, 2008), as well as some other films representing madness and asylums, such as Psycho (Alfred Hitchcock, 1960) and Girl, Interrupted (James Mangold, 1999), the role of water as a purification agent is subverted, most frequently by means of violent shower scenes.

As in these films, in Shutter Island the role of water as a purification agent is complicated and subverted, largely due to its significance in the mechanisms of Andrew's repression. Water is central to the memory Andrew relentlessly represses - his wife's drowning of their children. As a result of this repression, water in its various forms is a pivotal component of Andrew's delusional visions, and the uncanny re-emergence of his repressed memories. In addition, water serves as an uncanny thread between the delusional world of "Teddy" and Andrew's repressed past. The viewer's first vision of Andrew is of him vomiting in the ferry, overwhelmed by the wide expanse of water he sees through the boat's window. "Pull yourself together Teddy. It's just water, a lot of water", he tells himself in an attempt to calm his nerves. He then explains to his "partner” Chuck (Mark Ruffalo) that he "can't stomach the water”. Andrew's recollection of his dead wife, Dolores (Michelle Williams), is then juxtaposed with the roaring waves that lash against the boat.

Water continually re-emerges throughout the film as a link between the (diegetic) "real" and the world of Andrew's dreams and delusions. When Andrew dreams of holding a soaking Dolores as she crumbles into ash, he emerges from the embrace with dripping water cupped in his hands. He then awakes in distress as a leaky roof soaks him with water, and as in his dream, water drips through his cupped hands. A violent storm ravages the island for much of the film, mirroring Andrew's increasingly fractured mental state. His dreams, delusions and severe migraine are accompanied by the lashing of water against windows. In addition, a repeated vision of Andrew's soaking wife, accompanied by Andrew's apprehensive question, "Why are you all wet, baby?", serves as a signifier of the impending uncanny re-emergence of Andrew's repressed memories. Thus, water becomes a threatening and destabilising force for the protagonist, central to his unstable and subversive relationship with truth and reality. Because it is a central signifier of the mechanisms of Andrew's repression, its power as a purifying agent working for the side of reason is diminished and undermined. However, water also functions as a sign of truth - a haunting from the world of the real that Andrew has repressed. 
Water is also inherently connected to the island location, and the opposition between nature and culture which is inscribed upon the asylum. The first appearance of the island is of the craggy, rock cliffs which surround it, and, as a menacing soundtrack crescendos, the viewer is slowly drawn towards these cliffs through a forward moving wide-angled shot. As the cliffs come to fill more of the screen, the ferry driver points out that "the other side of the island is rock bluffs, all the way down to the water". These cliffs underscore the island's menacing danger, and its impenetrable borders. As well as emphasizing the island's physical segregation from the mainland, the prominence of these rocky cliffs, along with the thorny forests and violent storm which later ravages the island, unite the island with the volatile and uncontainable powers of nature. Thus, the powerful nature of the island is aligned with the power of madness to subvert and undermine rationality. This is particularly evidenced during the storm, as the team of psychologists discuss how they will contain the inmates when the violent storm cuts off the asylum's electricity. The next day, the psychologists' worst fears are realised, as in the storm-induced electricity shortage, inmates have escaped. The orderlies are seen chaotically trying to re-capture inmates while also clearing the thorny debris which has ravaged the pristine asylum gardens. Thus, working on the side of the mad inmates, the storm has the power to castrate the forces of confinement and control represented by the psychologists.

The unrestrained powers of nature signified by the island are juxtaposed with the imposing brick buildings of the asylum (one of which is "an abandoned Civil War fort"), barbed wire, overgrown graveyards and an ominous lighthouse which stands on the outermost edge of the jagged rock bluffs. The contrast between the unrestrained forces of nature and the man-made asylum buildings generates a fractured locale. This opposition between nature and culture, one which is homologous to the dichotomy between rationality and irrationality, becomes increasingly central to the depiction of the island asylum, further underscoring its power as an uncanny and unstable domain. In fact, the juxtaposition of the chaotic powers of nature and the brick buildings undermines the cold, suppressive rationality of the asylum, so that the asylum itself becomes imprinted with the anarchic instability of nature and madness.

Nature's ability to undermine the rational control of the asylum buildings reaches an apex in the representation of Ward C, the ward for the criminally insane. The "criminally insane" wards are frequently centralised as a source of terror in asylum horror films, also seen in Session 9 and Gothika. The inmates of these wards symbolise the pinnacle of madness's power to corrupt and wreak havoc upon the conventional restraints and structures of normal society. In Shutter Island Teddy asserts that Ward C is "where they keep the worst ones. Guys even the other inmates are scared of", and is marked by "constant screaming day and night”. The audience first encounters Ward C after the wild storm has cut off its electricity, causing the abject inmates within to run riot. The powers of nature seep into Ward $\mathrm{C}$ in the form of constantly dripping water, and orderlies are seen removing fallen trees from the grounds and roof of the asylum building. The central characters are required to dodge broken power lines and branches, including a large bough falling from the roof of the asylum building, to enter Ward C. The building seems to merge with the untamed wilderness which surrounds it; as seen in a number of aerial wide shots, the roof of the asylum is covered in a thick layer of moss, making it appear as though Ward $\mathrm{C}$ has emerged from the grassy earth of the island.

Ultimately, the island asylum figures a space of duality between internal and external worlds, the primal chaos of madness and the overbearing rationality of psychologists - as imaged through the conflicting visual juxtaposition of the severe and imposing asylum buildings and the volatile, thorny nature of the island, a dichotomy which remains a thematic undercurrent 
throughout the film through the ways in which storms and water intrude upon and disturb the coherence of the linear narrative. In Shutter Island this duality is further encoded by the conflict between the detective narrative and the narrative of delusion. The layering of both horror and film noir aesthetics positions the viewer in a space of disorientating hesitation, mirroring the vacillation between Andrew's internal and external realities. Thus, like Andrew and the other inmates of Shutter Island, at the end of the film the viewer is left stranded and adrift on this symbolic Ship of Fools.

\section{Works Cited}

Asylum. Dir. Roy Ward Baker. Amicus Productions, 1972.

Asylum. Dir. David R. Ellis. Hyde Park Films, 2008.

Casino. Dir. Martin Scorsese. Universal Pictures, 1995.

Departed, The. Dir. Martin Scorsese. Warner Bros Pictures, 2006.

Foucault, Michel. Madness and Civilization. Trans. David Cooper. Great Britain: Routledge Classics, 2001.

Girl, Interrupted. Dir. James Mangold. 3 Art Entertainment, 1999.

Goodfellas. Dir. Martin Scorsese. Warner Bros Pictures, 1990.

Gothika. Dir. Mathieu Kassovitz. Columbia Pictures Corporation, 2003.

Island of Doctor Moreau, The. Dir. Don Taylor. American International Pictures, 1977.

Island of Doctor Moreau, The. Dir. John Frankenheimer. New Line Cinema, 1996.

Lost. Dir. J.J. Abrams. ABC Studios, 2004-2010.

Mean Streets. Dir. Martin Scorsese. Warner Bros Pictures, 1973.

Papillon. Dir. Franklin Schaffner. Allied Artists Pictures, 1973.

Psycho. Dir. Alfred Hitchcock. Paramount Pictures, 1960.

Session 9. Dir. Brad Anderson. USA Films, 2001.

Shutter Island. Dir. Martin Scorcese. Paramount Pictures, 2010.

Taxi Driver. Dir. Martin Scorsese. Columbia Pictures Corporation, 1976.

Wells, H.G. The Island of Doctor Moreau. London: Bantam. 